\title{
Analisa Pieces Untuk Rancang Bangun Sistem Informasi Monitoring Persediaan Barang Berbasis Web Pada Koperasi Sartika Bogor
}

\author{
Siti Ernawati $^{1 *}$, Rizky Gumelar ${ }^{2}$ \\ ${ }^{1}$ Sistem Informasi, Sekolah Tinggi Manajemen Informatika dan Komputer Nusa Mandiri \\ Indonesia \\ ${ }^{2}$ Sistem Informasi, Universitas Bina Sarana Informatika \\ Indonesia
}

Email:siti.ste@nusamandiri.ac.id

\begin{abstract}
In the process of recording inventory in Sartika Cooperatives of Bogor still use a manual system. Problems that often occur in the manual process are errors in recording the amount of incoming goods and outgoing goods, the length of time in determining items that are out of stock and reporting of stock data is constrained. The solution obtained after analyzing the current system is to implement pieces analysis to build and implement a web inventory monitoring information system that aims to assist cooperatives in terms of monitoring inventory and reporting stock data faster and more accurate. To find out the benefits felt in building a proposed system researchers use pieces analysis so that the proposed system can provide maximum benefits in overcoming problems that exist in cooperatives.

Keywords: Inventory; Information Systems; Inventory Monitoring; Pieces Analysis; Cooperative
\end{abstract}

\begin{abstract}
Abstrak
Dalam proses pencatatan persediaan barang pada Koperasi Sartika Bogor masih menggunakan sistem yang manual. Permasalahan yang sering terjadi dalam proses manual adalah kesalahan dalam mencatat jumlah barang masuk dan keluar, lamanya dalam menentukan barang yang sudah habis stok serta pelaporan data stok menjadi terkendala. Solusi yang didapatkan setelah menganalisa sistem berjalan adalah mengimplementasikan analisa pieces untuk membangun dan mengimplementasikan sistem informasi monitoring persediaan barang berbasis web yang bertujuan untuk membantu koperasi dalam hal monitoring persediaan barang dan pelaporan data stok menjadi lebih cepat dan akurat. Untuk mengetahui manfaat yang dirasakan dalam membangun sistem usulan peneliti menggunakan analisa pieces agar sistem yang diusulkan dapat memberikan manfaat yang maksimal dalam mengatasi masalah yang ada pada koperasi.
\end{abstract}

Kata Kunci: Persediaan Barang; Sistem Informasi; Monitoring Persediaan; Analisa Pieces; Koperasi

\section{Pendahuluan}

Hasil penerapan dari perkembangan teknologi komputer sudah sangat luas, tidak hanya digunakan dalam bidang tertentu saja, akan tetapi hampir seluruh badan usaha kecil maupun besar sudah menggunakan 
komputer sebagai alat bantu kerja guna mempercepat proses kinerja dari badan usaha tersebut. Salah satu usaha yang bergerak dibidang koperasi pun membutuhkan teknologi komputer untuk membantu proses pengadaan barang dan untuk mencatat proses barang masuk dan keluar dari proses tersebut. Proses pengadaan barang itu sendiri merupakan suatu kegiatan untuk mengadakan atau menyediakan kebutuhan akan pasokan atau stok barang yang dibutuhkan.

Koperasi Sartika Bogor merupakan koperasi yang menyediakan barang dan jasa berupa ATK (alat tulis kantor), keperluan alat cetak, perlengkapan pegawai. Permasalahan yang dihadapi koperasi Sartika Bogor adalah ketidakmampuan koperasi dan manajemen dalam mendata secara akurat pemasukan dan pengeluaran barang setiap bulan, pencarian data yang masih dilakukan secara manual (Subhiyakto \& Safina, 2017), dalam proses yang masih dilakukan secara manual terkadang staf lupa untuk mencatat data persediaannya sehingga terjadi ketidaksesuaian antara data secara fisik dengan data dari pencatatan persediaan (Suhartono, Joni, Tri, 2018). serta pengambilan keputusan yang lambat diakibatkan pencatatan persediaan barang yang masih manual. Ketidakmampuan Koperasi Sartika dalam memperhitungkan barang yang masuk dan keluar dan menentukan data stok barang dapat mengakibatkan kerugian. Hal ini dapat dilihat, jika jumlah barang yang masuk atau disimpan didalam gudang berlimpah, maka perputaran modal dan keuntungan akan sangat lambat, pengeluaran menjadi besar dan ruang penyimpanan menjadi besar. Begitu pula sebaliknya, jika jumlah persediaan terlalu sedikit, maka permintaan tidak dapat dipenuh dan peluang memperoleh keuntungan lebih besar menjadi terhambat.

Salah satu faktor penting dalam mempertahankan kelangsungan usaha suatu instansi atau perusahaan adalah dengan adanya persediaan yang cukup untuk melayani permintaan dari pelanggan maupun untuk keperluan produksi. Jika persediaan menumpuk atau berlebihan maka akan mengakibatkan resiko dalam penyediaan dana atau modal kerja, peningkatan biaya penyimpanan, biaya pemeliharaan, biaya kesempatan dan resiko kerusakan persediaan (Fadly, Suhendro, \& Putra, 2019).

Dalam menghadapi teknologi informasi yang sudah berkembang dengan pesat ini, instansi atau perusahaan membutuhkan suatu sistem untuk meningkatkan kualitas pelayanan, sehingga kebutuhan akan suatu sistem informasi yang handal sangat diperlukan (Nulhakim, Azizah, \& Ajija, 2018). Hal tersebut diakibatkan karena 
banyaknya data yang harus diolah kemudian disajikan dalam bentuk informasi yang bermanfaat, sehingga manajemen dalam sebuah perusahaan atau instansi tersebut dapat mengambil suatu keputusan dengan cepat dan akurat. Sistem informasi monitoring persediaan barang sangat diperlukan dalam mengelola persediaan barang suatu perusahaan atau instansi agar tidak terjadi kehabisan stok atau penumpukan stok.

Tujuan dalam penelitian ini adalah menganalisa sistem persediaan barang yang sedang berjalan pada Koperasi Sartika Bogor, menerapkan analisa pieces untuk mengoreksi atau memperbaiki sistem informasi apakah sistem informasi yang dibangun dapat memberikan manfaat yang besar bagi Koperasi Sartika Bogor sehingga memudahkan proses penyampaiannya laporan informasi ke kantor pusat (Agusvianto, 2017) serta merancang dan mengimplementasikan sistem pemantauan inventori agar barang tidak berlebihan atau kekurangan (Jufri \& Zakaria, 2019).

\section{Bahan dan Metode}

\subsection{Metode Penelitian}

Metode penelitian yang digunakan adalah metode kualitatif (Irnawati, 2018) dimana peneliti harus melakukan proses observasi dengan cara melihat secara langsung proses persediaan barang yang meliputi stok masuk dan stok keluar yang terjadi di Koperasi Sartika Bogor. Selain observasi peneliti juga melakukan wawancara kepada bagian terkait agar data yang diperoleh lebih jelas dan akurat.

Model untuk analisa sistem berjalan menuju sistem usulan peneliti menggunakan analisa pieces. Analisa pieces merupakan tahapan proses untuk mengoreksi atau memperbaiki sistem informasi bagi pengambil keputusan dalam suatu organisasi. Berikut langkah-langkah analisis yang ada pada pieces (Al Fatta, 2007):

a. Analinsa Kinerja (Performance)

Dalam tahap analisa ini diukur dengan jumlah produksi dan waktu tanggap.

b. Analisa Informasi (Information)

Analisa terhadap kemampuan dari sistem informasi dalam menghasilkan informasi yang sangat bermanfaat untuk menghasilkan solusi atas masalah yang sedang terjadi.

c. Analisa Ekonomi (Economy)

Dalam proses analisa ini selalu berkaitan mengenai persoalan ekonomi yang berkaitan dengan masalah biaya.

d. Analisa Keamanan (Control) Analisa ini dilakukan untuk meningkatkan kinerja sistem, mencegah atau mendeteksi kesalahan dari sistem, menjamin keamanan dan kerahasiaan data. 


\section{e. Analisa Efisiensi (Eficiency)}

Dalam langkah analisis ini bagaimana menghasilkan output atau luaran yang sebanyak-banyaknya dengan input yang seminimal mungkin. Karena jika input dilakukan secara berlebihan akan membuat sistem tidak berjalan dengan efisien.

\section{f. Analisa Pelayanan (Services)}

Tahapan analisa ini untuk menilai suatu sistem mengenai layanan yang disediakan atau diberikan oleh sistem.

\subsection{Sistem Informasi}

Sistem informasi merupakan sistem yang terdiri dari kegiatan mengumpulkan, memproses, menyimpan, menganalisis, menyebarkan informasi untuk mencapai suatu tujuan tertentu. Sistem informasi berperan dalam proses pengambilan suatu keputusan operasional harian sampai dengan perancanaan dalam jangka Panjang (Meisak, 2017).

\subsection{UML (Unified Modeling Language)}

UML (Unified Modeling Language) adalah salah satu standar bahasa yang banyak digunakan di dunia industri untuk mendefinisikan requirement, membuat analisis dan desain, serta menggambarkan arsitektur dalam pemrograman berorientasi objek (Sukamto \& Shalahudin, 2018).

\section{Hasil dan Diskusi}

\subsection{Tahapan Penelitian}

Penelitian ini menggunakan analisis pieces untuk menentukan rancang bangun sistem informasi monitoring persediaan barang berbasis web yang akan dibuat. Langkah penyelesaian penelitian yang dilakukan adalah:

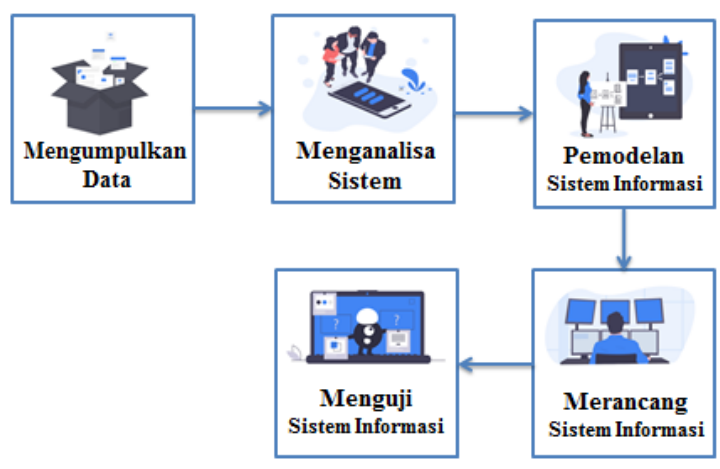

\section{Gambar 1 Tahapan Penelitian}

Berikut penjelasan mengenai langkahlangkah penyelesaian penelitian yang dilakukan:

1. Mengumpulkan Data

Mengumpulkan data untuk proses monitoring persediaan barang yang terjadi pada Koperasi Sartika Bogor. Data yang terkait diantaranya adalah data barang, data bagian dan proses masuk dan keluar barang.

2. Menganalisa Sistem

Dalam proses analisa yang dilakukan terdapat dua tahapan yaitu analisa terhadap sistem yang berjalan dan analisa terhadap sistem yang diusulkan. Dalam menganalisis sistem berjalan peneliti menggunakan tahapan analisis pieces 
yang mana dari tahap analisis ini akan menentukan bentuk system yang selanjutnya akan diusulkan dan dibangun (Nawang, Kurniawati, \& Duta, 2017).

3. Pemodelan Sistem Informasi

Langkah ini merupakan pembuatan model dari sistem informasi yang dibuat dengan menggunakan UML.

4. Merancang Sistem Informasi

Proses merancang sistem informasi dilakukan untuk membuat aplikasi sistem informasi monitoring persediaan barang berbasis website sesuai dengan kebutuhan user.

5. Menguji Sistem Informasi

Proses pengujian dilakukan agar menghindari kesalahan sistem dan sistem yang dibuat sesuai dengan kebutuhan user.

\subsection{Analisa Sistem Berjalan}

Berdasarkan penelitian yang telah dilakukan sistem pencatatan persediaan barang yang terjadi pada Koperasi Sartika Bogor masih manual (menggunakan tulisan tangan) dalam mencatat barang yang masuk dan keluar serta melaporkan data stok barang dapat mengakibatkan kesalahan dan kurang efektif sehingga dapat menjadikan kerugian bagi pihak koperasi jika terjadi kesalahan penulisan.

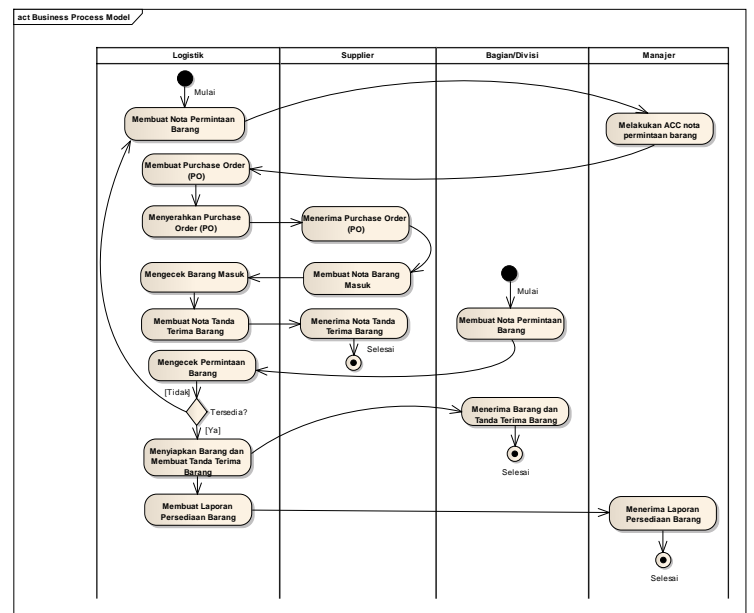

Gambar 2 Activity Diagram Sistem Berjalan

\subsection{Analisa Sistem Usulan}

Analisa yang diusulkan menggunakan proses analisis pieces. Berikut adalah penjelasannya:

a. Analisa Kinerja (Performance)

Mengukur sejauh mana sistem informasi memiliki kinerja yang maksimal atau kemampuan untuk menghasilkan suatu tujuan yang diinginkan oleh instansi atau perusahaan.

\section{Tabel 1 Hasil Analisa Kinerja (Performance)}

\begin{tabular}{|c|c|}
\hline Sistem Berjalan & Sistem Usulan \\
\hline $\begin{array}{l}\text { Pencatatan data } \\
\text { barang masuk, } \\
\text { barang keluar dan } \\
\text { pembuatan laporan } \\
\text { masih } \\
\text { menggunakan }\end{array}$ & $\begin{array}{l}\text { Data barang masuk } \\
\text { dan keluar dapat } \\
\text { diinput melalui } \\
\text { aplikasi berbasis } \\
\text { website begitu juga } \\
\text { untuk laporan dapat }\end{array}$ \\
\hline $\begin{array}{l}\text { tulisan tangan } \\
\text { sehingga } \\
\text { membutuhkan } \\
\text { waktu }\end{array}$ & $\begin{array}{l}\text { dicetak dan } \\
\text { ditampilkan } \\
\text { melalui aplikasi } \\
\text { berbasis web. }\end{array}$ \\
\hline $\begin{array}{l}\text { yang cukup lama } \\
\text { serta penyimpanan }\end{array}$ & $\begin{array}{l}\text { Kinerja yang } \\
\text { dihasilkan sistem }\end{array}$ \\
\hline
\end{tabular}




\begin{tabular}{ll}
\hline \multicolumn{1}{c}{ Sistem Berjalan } & \multicolumn{1}{c}{ Sistem Usulan } \\
\hline data masih berupa & menjadi lebih \\
arsip (hardcopy) & cepat dan \\
& penyimpanan data \\
& sudah terintegrasi \\
& dalam sebuah \\
& database \\
\hline
\end{tabular}

b. Analisa Informasi (Information)

Proses evaluasi mengenai kemampuan dari sistem informasi yang dibangun untuk menghasilkan output berupa informasi yang bermanfaat, proses analisa ini dilakukan agar instansi atau perusahaan dapat menyikapi peluang yang ada dan menangani masalah yang terjadi.

\section{Tabel 2 Hasil Analisa Informasi (Information)}

\begin{tabular}{lrlr}
\hline \multicolumn{2}{c}{ Sistem Berjalan } & \multicolumn{2}{c}{ Sistem Usulan } \\
\hline Data & stok barang & Data stok & diinput \\
yang masuk dan & melalui & sistem \\
yang keluar masih & informasi & sehingga \\
dicatat manual & lebih & \\
melalui & kertas & cepat & dan \\
sehingga dapat & update & dan \\
terjadi human error & informasi & yang \\
karena salah tulis & disajikan & lebih \\
dan anan & terstruktur & \\
mengakibatkan & & \\
kerugian bagi & & \\
koperasi dan & & \\
informasi yang & & \\
akan diberikan & \\
tidak valid ran & & \\
\hline
\end{tabular}

c. Analisa Ekonomi (Economy)

Dalam proses analisa ini selalu berkaitan mengenai persoalan ekonomi yang berkaitan dengan masalah biaya, karena pijakan dasar bagi kebanyakan pimpinan adalah biaya atau uang.

\section{Tabel 3 Hasil Analisa Ekonomi (Economy)}

\begin{tabular}{lll}
\hline \multicolumn{2}{l}{ Sistem Berjalan } & \multicolumn{2}{l}{ Sistem Usulan } \\
\hline Biaya pengadaan & Dalam sistem \\
kertas untuk & informasi usulan, \\
mencetak dan & penyimpanan data \\
menulisa data yang & sudah \\
ada dalam koperasi & menggunakan \\
cukup mahal dalam & database, sehingga \\
jangka waktu yang & penyimpanan data \\
panjang, & lebih terstruktur \\
membutuhkan & dan lebih hemat \\
banyak pegawai & dalam jangka \\
untuk mencatat & waktu yang \\
data-data yang & panjang dan tidak \\
dibutuhkan & membutuhkan \\
& banyak pegawai \\
& untuk menginput \\
& data-data yang \\
& dibutuhkan \\
\hline
\end{tabular}

d. Analisa Keamanan (Control)

Proses analisa ini dilakukan untuk meningkatkan kinerja dari sistem informasi, mendeteksi bahkan mencegah kesalahan yang terjadi pada sistem informasi dan menjamin keamanan dan kerahasiaan data yang ada pada sistem informasi.

\section{Tabel 4 Hasil Analisa Keamanan (Control)}

\begin{tabular}{lrlr}
\hline \multicolumn{2}{c}{ Sistem Berjalan } & \multicolumn{2}{c}{ Sistem Usulan } \\
\hline Keamanan data & Keamanan & yang \\
belum terjamin, & diberikan & dalam \\
karena belum ada & sistem & usulan ini \\
backup data & dan & lebih & terjamin \\
\hline
\end{tabular}




\begin{tabular}{lrlr}
\hline \multicolumn{2}{c}{ Sistem Berjalan } & \multicolumn{2}{c}{ Sistem Usulan } \\
\hline semua & dokumen & karena & adanya \\
masih & dalam & backup data dan \\
bentuk & kertas & untuk hak akses \\
sehingga & rentan & dalam \\
terjadi & kerusakan & menggunakan \\
pada & dokumen & sistem informasi \\
tersebut & & lebih jelas karena \\
& & adanya username \\
& & dan & password \\
& & untuk setiap user \\
\hline
\end{tabular}

e. Analisa Efisiensi (Eficiency)

Analisa ini terkait dengan bagaimana sistem informasi yang dibuat menghasilkan luaran yang sebanyakbanyaknya dengan input yang seminimal mungkin.

\section{Tabel 5 Hasil Analisa Efisiensi (Eficiency)}

\begin{tabular}{lrlr}
\hline \multicolumn{2}{c}{ Sistem Berjalan } & \multicolumn{2}{c}{ Sistem Usulan } \\
\hline Dalam proses & Sistem informasi \\
melaporkan data & yang diusulkan \\
membutuhkan & memberikan \\
waktu yang cukup & kemudahan untuk \\
lama karena harus & user dalam hal \\
mengecek data & pelaporan, karena \\
yang ada dalam & dalam & sistem \\
data barang masuk & informasi \\
dan data barang & disediakan renu \\
keluar & & untuk menampilkan \\
& & laporan r dan \\
& & \multicolumn{2}{c}{ mencetak laporan } \\
\hline
\end{tabular}

f. Analisa Pelayanan (Services)

Kualitas dari sistem informasi salah satunya adalah dapat meningkatkan pelayanan bagi pengguna sistem. Salah satu dari kriteria dalam analisa pelayanan ini adalah apakah sistem mudah dipakai (user friendly) dan mudah dipelajari.

Tabel 6 Hasil Analisa Pelayanan (Service)

\begin{tabular}{ll}
\hline \multicolumn{1}{c}{ Sistem Berjalan } & \multicolumn{2}{c}{ Sistem Usulan } \\
\hline Keterlambatan & Sistem informasi \\
dalam melaporkan & yang diusulkan \\
data persediaan & mengurangi \\
kepada pimpinan & keteralambatan \\
& dalam melaporkan \\
& datapersediaan \\
& kepada pimpinan \\
& sehingga dapat \\
& meningkatkan \\
& pelayanan \\
\hline
\end{tabular}

\subsection{Pemodelan Sistem Informasi}

Tahap penelitian selanjutnya adalah membuat pemodelan sistem informasi monitoring persediaan barang. Untuk pemodelan sistem informasi monitoring persediaan barang menggunakan UML (Unified Modeling Language) sebagai gambaran bentuk dari alur sistem yang diusulkan.

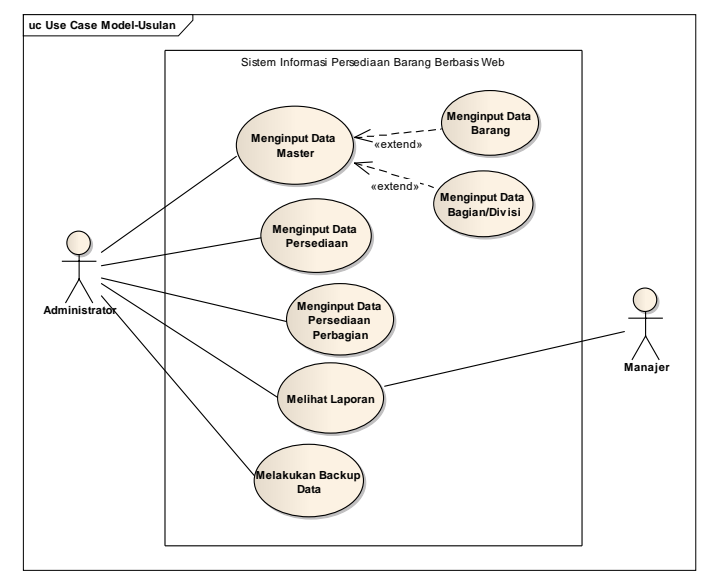

Gambar 3 Use Case Diagram Sistem Usulan 
Berikut adalah entity relationship diagram untuk sistem informasi monitoring persediaan barang berbasis web.

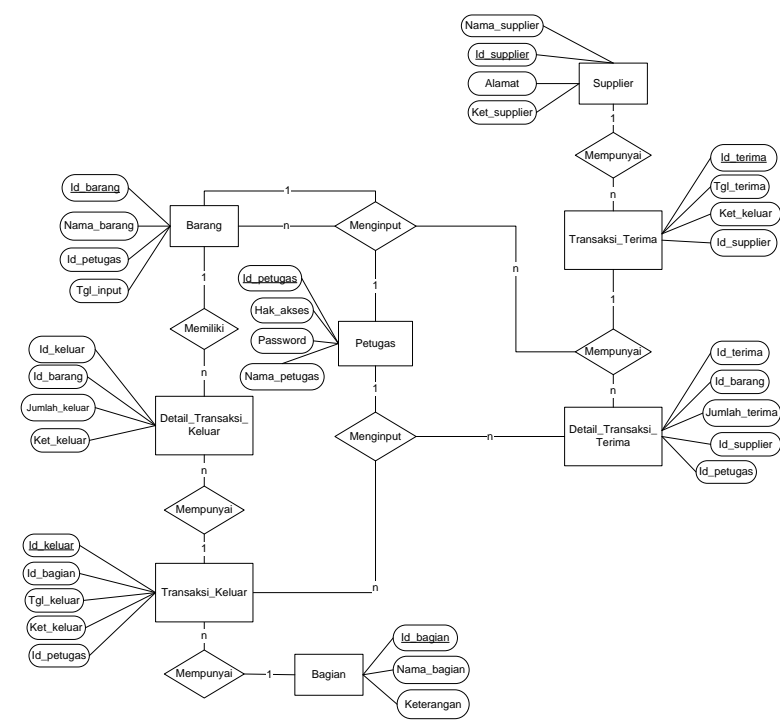

Gambar 4 Entity Relationship Diagram

\subsection{Implementasi Antarmuka}

Berikut merupakan implementasi antarmuka yang dibuat untuk sistem informasi monitoring persediaan barang berbasis web yang telah dibuat.

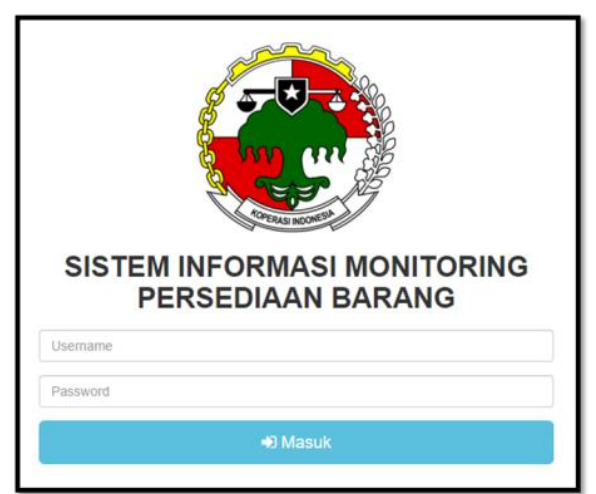

Gambar 5 Halaman Login Sistem Informasi Monitoring Persediaan Barang

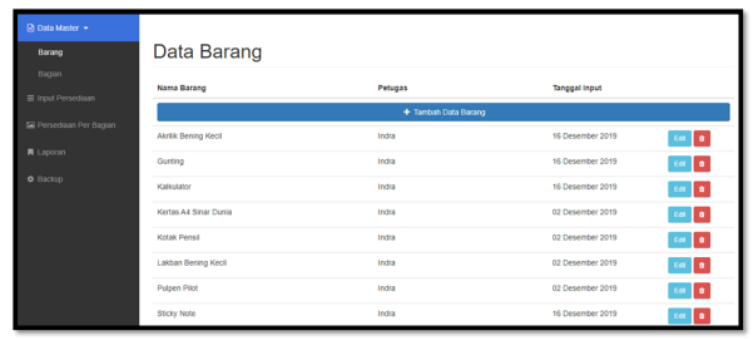

Gambar 6 Halaman Data Barang

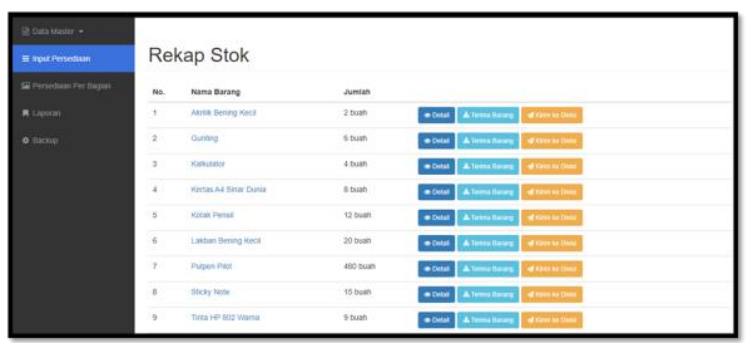

Gambar 7 Halaman Rekap Stok

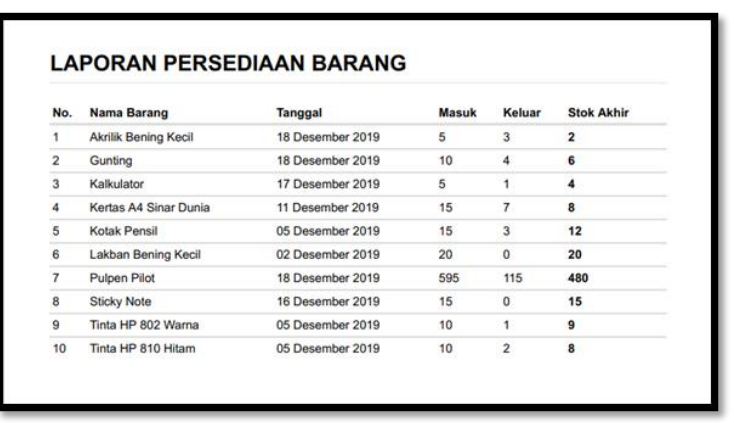

Gambar 8 Laporan Persediaan Barang

\subsection{Pengujian Sistem Informasi}

sistem informasi membutuhkan pengujian untuk menentukan tingkat keberhasilan sistem yang dibangun (Larasati, 2018). Dalam melakukan pengujian sistem informasi yang telah dibuat peneliti menggunakan blackbox testing. Pengujian ini dilakukan untuk menentukan apakah sistem informasi yang diusulkan berjalan sesuai dengan harapan atau tidak. 


\section{Tabel 7 Pengujian sistem informasi Tambah Persediaan}

\begin{tabular}{|c|c|c|c|}
\hline $\begin{array}{c}\text { Skenario } \\
\text { pengujian }\end{array}$ & Test case & $\begin{array}{c}\text { Hasil yang } \\
\text { diharapkan }\end{array}$ & $\begin{array}{c}\text { Hasil } \\
\text { Pengujian }\end{array}$ \\
\hline $\begin{array}{l}\text { Tanggal, } \\
\text { Jumlah } \\
\text { Terima dan } \\
\text { Keterangan } \\
\text { dikosongkan } \\
\text { kemudian } \\
\text { klik Simpan }\end{array}$ & $\begin{array}{l}\text { Tanggal : } \\
\text { (Kosong) } \\
\text { nJumlah } \\
\text { Terima : } \\
\text { (Kosong) } \\
\text { Keterangan } \\
: \text { (Kosong) }\end{array}$ & $\begin{array}{l}\text { Sistem akan } \\
\text { menolak akses } \\
\text { user dan } \\
\text { menampilkan } \\
\text { "Mohon } \\
\text { mengisi data } \\
\text { di kolom yang } \\
\text { sudah } \\
\text { disediakan } \\
\text { dengan } \\
\text { lengkap" }\end{array}$ & $\begin{array}{c}\text { Sesuai } \\
\text { Harapan }\end{array}$ \\
\hline $\begin{array}{l}\text { Menginput } \\
\text { Tanggal, } \\
\text { Jumlah } \\
\text { Terima dan } \\
\text { Keterangan } \\
\text { dikosongkan } \\
\text { kemudian } \\
\text { klik Simpan }\end{array}$ & $\begin{array}{l}\text { Tanggal : } \\
\text { (Terisi) } \\
\text { Jumlah } \\
\text { nTerima : } \\
\text { (Kosong) } \\
\text { Keterangan } \\
\text { : (Kosong) }\end{array}$ & $\begin{array}{l}\text { Sistem akan } \\
\text { menolak akses } \\
\text { user dan } \\
\text { menampilkan } \\
\text { "Mohon } \\
\text { mengisi data } \\
\text { di kolom yang } \\
\text { sudah } \\
\text { disediakan } \\
\text { dengan } \\
\text { lengkap" }\end{array}$ & $\begin{array}{l}\text { Ses } \\
\text { Hare }\end{array}$ \\
\hline $\begin{array}{l}\text { Menginput } \\
\text { Tanggal, } \\
\text { Jumlah } \\
\text { Terima dan } \\
\text { Keterangan } \\
\text { kemudian } \\
\text { klik Simpan }\end{array}$ & $\begin{array}{l}\text { Tanggal : } \\
\text { (Terisi) } \\
\text { Jumlah } \\
\text { nTerima : } \\
\text { (Terisi) } \\
\text { Keteranga } \\
: \text { (Terisi) }\end{array}$ & $\begin{array}{l}\text { Sistem akan } \\
\text { menyimpan } \\
\text { data dan } \\
\text { menampilkan } \\
\text { "Berhasil } \\
\text { menyimpan } \\
\text { data" }\end{array}$ & $\begin{array}{c}\text { Sesuai } \\
\text { Harapan }\end{array}$ \\
\hline
\end{tabular}

\subsection{Kesimpulan}

Dengan adanya sistem informasi monitoring persediaan barang berbasis web ini, dapat membantu Koperasi Sartika Bogor dalam pengolahan data persediaan barang. Selain itu dapat meminimalisir kesalahan-kesalahan seperti human error yang terjadi pada sistem yang masih belum terkomputerisasi. Proses penyimpanan data yang mengunakan database akan menjamin kerahasian data dan keamanan data lebih terjamin karena setiap user yang akan mengakses diberikan username dan password serta data dapat disimpan dalam jumlah yang besar sehinggaa tidak memerlukan banyak tempat dan tidak mudah rusak atau hilang serta membantu proses pembuatan laporan lebih cepat dan akurat.

\subsection{Ucapan Terima Kasih}

Alhamdulillah puji syukur kami panjatkan kepada Allah swt, karena atas ridhaNya kami dapat menyelesaikan penelitian ini. Tak lupa kami ucapkan banyak terima kasih kepada segenap pihak yang telah memberikan do'a dan dukungan kepada peneliti dalam menyelesaikan penelitian ini. Beserta tim redaksi jurnal Evolusi yang telah menelaah dan mereview jurnal yang peneliti buat sampai dengan proses penerbitan jurnal.

\subsection{Referensi}

[1] Agusvianto, H. (2017). Sistem Informasi Inventori Gudang Untuk Mengontrol Persediaan Barang Pada Gudang Studi Kasus: PT.Alaisys Sidoarjo. Journal of Information Engineering and Educational Technology, 1(1).

[2] Al Fatta, H. (2007). Analisis \& Perancangan Sistem Informasi untuk Keunggulan Bersaing Perusahaan \& 
Organisasi Modern. (A. Triyuliana, Heni, Ed.). Yogyakarta: ANDI.

[3] Fadly, M., Suhendro, D., \& Putra, A. (2019). Perancangan Aplikasi Persediaan Barang dan Bahan Makanan Menggunakan Metode FIFO pada KFC Pematangsiantar. Jurnal Ilmiah Media Sisfo, 13(1), 48-58. http://doi.org/https://doi.org/10.33998 /mediasisfo.2019.13.1.527

[4] Fathansyah. 2007. Buku Teks Komputer Basis Data. Bandung: Informatika Bandung.

[5] Irnawati, O. (2018). Implementasi Metode Waterfall Pada Sistem Informasi Stock Opname. Indonesian Journal on Software Engineering, 4(1), 79-84.

[6] Jufri, F. R., \& Zakaria, T. M. (2019). Rancang Bangun Aplikasi Inventori Barang untuk Fajar Jaya Abadi Memanfaatkan " Laravel Framework . Jurnal Strategi, 1(1), 246-260. Retrieved from http://strategi.it.maranatha.edu/index. php/strategi/article/view/49

[7] Larasati, O. (2018). Sistem Informasi Inventory Barang Koperasi Karyawan Perhutani Cepu Berbasis Web. Jurnal Mitra Manajemen, 2(6), 586-596. Retrieved from http://ejurnalmitramanajemen.com/index.php /jmm/article/view/161
[8] Meisak, D. (2017). Analisis dan Perancangan Sistem Informasi Persediaan Barang Menggunakan Metode FIFO Pada PT.Shukaku Jambi. Jurnal Ilmiah Media Sisfo, 11(2), 862-875.

[9] Nawang, M., Kurniawati, L., \& Duta, D. (2017). Rancang Bangun Sistem Informasi Pengolahan Data Persediaan Barang Berbasis Dekstop dengan Model Waterfall. PILAR, 13(2), 233-238.

[10] Nulhakim, L., Azizah, N., \& Ajija, M. T. (2018). Sistem Informasi Monitoring Inventory Dengan Analisa PIECES Pada PT. Care Spundbond. Prosiding SENSITEK, 480-485.

[11] Subhiyakto, E. R., \& Safina, N. (2017). Rancang Bangun Sistem Informasi Inventaris BPJS Ketenagakerjaan Cabang Pekalongan. Jurnal Sains Dan Teknologi, 6(1), 7281. Retrieved from https://ejournal.undiksha.ac.id/index.p hp/JST/article/view/9064

[12] Suhartono, Joni, Tri, T. (2018). Perancangan System Informasi Persediaan Untuk Memonitoring Stock Barang. Journal of Technology Information, 4(1), 46-51.

[13] Sukamto, R. A., \& Shalahudin, M. (2018). Rekayasa Perangkat Lunak Terstruktur dan Berorientasi Objek. 
Bandung: Informatika.

[14] Sutabri, Tata. 2012. Analisis Sistem

Informasi. Yogyakarta: CV. Andi

Offset.

[15] Sutopo, Arieto Hadi. 2007.

Pemograman Flash dengan PHP dan

MySQL. Yogyakarta: Graha Ilmu. 